\title{
Noise pollution at school environment: review study of China and South Africa cases
}

\author{
Chaimae El Yamlahi Chahdi ${ }^{1,2^{*}}$, Bouazza El Wahbi ${ }^{2}$, Youssef El Madhi ${ }^{3}$, Hajar DARIF ${ }^{2}$,Hanan EL FAYLALI², And \\ Abdelmajid SOULAYMANI
}

\author{
${ }^{1}$ Research Laboratory Innovation \& Information System, EuRSED Vienne France \\ ${ }^{2}$ Faculty of Sciences, Ibn Tofail University, Morocco \\ ${ }^{3}$ Research Laboratory: Education, Environment \& Health, CRMEF Rabat, Morocco
}

\begin{abstract}
Today, noise pollution in educational institutions presents a serious problematic pushing the world to work on finding durable solutions. Many recent studies have been conducted in many countries for the purpose of reducing and maintaining ambient noise levels inside the school environment to the adequate level, to provide good teaching and learning conditions for both teachers and students. The two articles treating noise pollution at school environment in South Africa and in China, were analysed in this review in order to present different solutions to this problem and their adequacy to maintain noise pollution in scholar environment.
\end{abstract}

Keywords: Noise, Noise pollution, School environment, Classroom, Decibel, Amplification system, SoundEar

\section{INTRODUCTION}

According to the definition found in the Oxford dictionary, noise is "'A sound, especially one that is loud or unpleasant or that causes disturbance."“" which means an unwanted sound, constantly happening, that harms the human body specifically the ears.

Noise pollution called also environmental noise is an undesired excessive sound with damaging effects on human health and his living quality. Noise pollution is, basically, engendered from side-by-side outdoor activities as heavy industry manufactories and from daily dynamic operations like air traffic, highways and railways.

Noise Pollution in the School Environment is an aching issue that detriment the educational system staff, consisting of students; teachers and school management crew, not just in their professional life but also in their personal life. Background noise refers to two principal categories: External and internal sources [1]. The external sources are generally related to neighbourhood traffic and noisy activities around. The internal sources are linked to voices produced by students, teachers and all the employees inside the school.

Recent studies have demonstrated that noise has a negative impact to the global institution's performance $[2,3,4]$. It affects learning process, attention and memory abilities and motivation for studying.

Most countries have achieved remarkable results to reduce it. They first, started diagnosing its dimensions from different perspectives: human factors; environment factors; regulatory standards and others. Then, analysed the initial status in both qualitative and quantitative forms. Consequently, tried to manage the extracted dysfunctions by putting in place corrective and ameliorative action plans.

Since China and South Africa are one of the countries with the worst level of noise pollution [5], they were seriously engaged to change this fact by lots of researches. This review intends to cite what two selected studies of China and South Africa has been doing to maintain noise pollution in school environment and the results of their work.

\section{METHODS}

The research goal is to clarify the methods used to reduce noise pollution in schools in both China and South Africa. Reducing background noise is considered as a key factor for good speech intelligibility during teaching [6]. To achieve this purpose, different methods were utilized in the two studies.

The first study took place in Hong Kong, since it is one of the most cities in China with higher population density than states in North America and Australia [7], which increases noise levels [8]. By implementing portable and fixed amplification systems, it attempted to: - Determines sound level of background noise in occupied classrooms and their educational environment.

\footnotetext{
* Chaimae El Yamlahi Chahdi: elyamlahi.chahdi.chaimae@gmail.com
} 
- Determines their effects on teacher's speech level during teaching and learning process.

The data were registered between 2008 and 2010 by using specific procedures for acoustical measurement. It took place in 37 schools composed of kindergartens, primary and secondary levels and special categories in Hong Kong. To demonstrate a representative range of classroom environments of this big city, 248 sites were picked for measurement. 231 of 248 sites were successfully examined, divided into 146 measurements in closed classrooms and 85 in playgrounds. Half of these $(42 / 85)$ were covered.

Most of the schools were located in quiet areas far from noisy traffic. About a quarter were near of main roads, just over a third were near of secondary roads and almost a half were in quiet zones.

Brüel and Kjær sound level meter was used to measure two types of measurements during teaching: noise and speech levels. First type was measured when there was no talking from students or teachers so that only external sound was present. Second type was obtained when teachers were addressing a teaching speech in classroom. The average of three samples of 10 seconds was taken. The acoustic parameters of noise and speech for the 10s samples were recorded and indicate the low level (LAmin, 10s), high level (LAmax, 10s), and the average level (LAeq, 10s). The measurement took place at one location centred in the middle of each classroom. The unamplified speech was recorded by a distance of $1 \mathrm{~m}$, and the amplified one recorded by a distance of $1.5 \mathrm{~m}$. The average speech values were deducted from the average noise values to derive a speech to noise ratio (SNR) of each classroom.

The second study of South Africa took place in two primary schools in Tshwane west funded by the government. The selected classrooms covered grades from 1 to 3. It managed two phases:

- During phase one, noise measurement took place in three classrooms for 36 hours. In order to decide about the SoundEar II feasibility, an experimental program was installed at the first school. The program took in consideration the school's settings. After that, the instrument was fixed on the classroom. The same operation took place in the second school.

- During phase two, 06 female teachers aged between 26 and 60 years old, from the 02 schools completed a descriptive questionnaire [9]. It describes their personal participation using the instrument SoundEar II. The six teachers' observations were analysed systematically and compared to the data stored through the SoundLog software.

Teachers were designated to work in selected classrooms from the three levels. The 1st grade's classroom composed of 35 students, the 2nd grade's classroom had 40 students and the 3 rd grade's classroom had 39 students.

The device was pre-set to a level limit of $80 \mathrm{~dB}$. Its noise limits ranged from $40 \mathrm{~dB}$ to $115 \mathrm{~dB}$ with the possibility of being changed at any level. The device screen displays three LED lights indicating the actual noise level [10]. The green light means that the noise level in the classroom is below the pre-set limit which is considered suitable. The yellow light means that the noise level is close to the pre-set limit which requires actions in order to lower the noise level. The red light means that the noise level had surpass the pre-set limit which urgently requires immediate actions. During the intervention, visual feedback was collected to maintain the track of noise level.

The SoundLog software main function is to provide displayed results after treatments. Using a desktop, the program interconnects the device with the computer, which allows data to be downloaded, viewed and analyzed in Excel. Its role was to calculate noise level average, standard deviation, max level and min level in both phases: the baseline and intervention.

\section{RESULTS}

The two studies of China and South Africa conducted significant results. Although these findings were not satisfactory in order to maintain noise pollution at the adequate level, they nevertheless made a remarkable change, especially when talking about the big city of Hong Kong. The involvement of the human factor to achieve the objective of the studies was a smart adding and a good attempt to reduce this environmental pollution.

China research interested in using sound amplification systems of both technologies portable and fixed, to help clarify teachers' speech over the ambient noise. The statistical results clarify that all the sound levels inside classrooms are over the recommended level, which is $50 \mathrm{Db}$ [11]. Despite the school's building, location and dimensions, there was no difference in sound level. Moreover, there was a non-significant Intra Class Correlation.

To evaluate the impact of students age on sound level inside classrooms, special schools were excluded because their students are not grouped into class. The Means, SD and ranges calculated from average background noise levels $(\mathrm{dB})$ in closed classrooms were measured according to class grade [6]. Measured speech level using a sound amplification system was higher than levels without technologies assistance. To display results of teachers' speech level linked to classrooms' noise level, a scatter plot was used. The correlation was statistically expressive. The increasing of speech level is correlated to the increasing of noise level by a linear regression. It is drawn with the equation $(\mathrm{y}=0.44 \mathrm{x}+$ 46.79). The result concludes that for each $1 \mathrm{~dB}$ raise in noise level, the teacher's speech level raised by $0.44 \mathrm{~dB}$ [6].

Less than half of classrooms installed fixed and portable amplification systems. Most of them were for portable devices and a small minority were for fixed ones. Tests concluded that SNR in classrooms with amplification was higher than ones without it [6]. Most schools had measures with noise diminution (approximately three quarters had one diminution measure). Three quarters of classrooms used installed cork bulletin boards. No school used equipment that are 
acoustically modified and only few ones used acoustical barriers, carpets, acoustic or ceiling tiles.

To conclude with, this study proved that noise level in occupied classrooms in Hong Kong exceeded the recommended levels, more than unoccupied ones $[12,13]$. Statistical evaluations confirmed that there is no connection between the ambient noise and the age of the school structure, classrooms implementation, dimensions or students grades. Teachers' speech level had a significant correlation with the measured noise level. It is highly recommended to use fixed or portable amplification systems in order to offer suitable SNR for the teaching and learning process.

South Africa research shown the effect of visual feedback on noise level inside classrooms by using a SoundEar II instrument. It worked using two sorts of methods as project's phases: technological and pedagogical tools. First tool was implementing visual feedback device for ambient noise helping both teachers and students to self-control their noise levels. Second tool was to exploit results from questionnaires completed by participated teachers in order to maintain the amelioration of corrective actions.

At the end of phase one and after analyzing the collected data. During the baseline phase, noise levels surpassed $70 \mathrm{~dB}$ just over a third of the time, while it surpassed only a quarter during the intervention phase. They surpassed $80 \mathrm{~dB}$ during the baseline three quarters of the time, whilst it surpassed only a small fraction during the intervention. The measurements surpassed 90 $\mathrm{dB}$ during the baseline $0.4 \%$ of the time, while during the intervention; it surpassed only $0.2 \%$.

The findings of phase two vary depending on: effects on learners, perceived benefits and disadvantages, ease of use, preference as permanent classroom aid and participated teachers' recommendations and comments.

\section{DISCUSSION}

\subsection{China study}

The main objectives of the study were to identify the background noise, which refers to voices that prevent a person's capability to listen to what they prefer to hear [14], in occupied classrooms in an Asian environment. Also, to determine the parameters influencing the background noise. The results presented above conclude numerous observations: All schools were affected by the background noise that surpass $50 \mathrm{~dB}$ which is the recommended level [11]. In all the four classroom categories, noise levels collected were extended between 67 and $70 \mathrm{~dB}$.

Without amplification systems, the average teachers' speech level was $74.22 \mathrm{~dB}$, which is higher than the speech level of a normal conversation $(65 \mathrm{~dB})$ [6]. The speech level increased as the noise level increased. This leads to a rise of teachers' voices to cover the noise inside classrooms. The amplification solution was not an optimum one, because there was only a $0.44 \mathrm{~dB}$ raise in speech level with every $1 \mathrm{~dB}$ raise in noise. Otherwise, this solution helps to improve the SNR in classrooms by improving the speech level only [11].

The research confirms that the schools' location, classroom dimensions, students' age range and the nature of lesson doesn't impact the background noise in active classrooms. Even though, the acoustical improvements existed in classrooms were limited. Adequate measures have been displayed and it is related to the number of installed acoustical treatments. Classroom noise level was not entirely affected after using amplification devices.

Referring to the results, the SNR was negatively impacted in the active classrooms. Without an amplification device, SNR was $6.82 \mathrm{~dB}$. It appears that in most of schools, student's performance was affected, especially in language, reading $[15,16]$, ability to memorize and be motived [17]. The case matters younger pupils because they request for understanding higher SNR [14]. High noise levels exist heavily in schools with multilingual characteristic. One of the most city having this issue is Hong Kong. In this large city, almost all of the inhabitants natively speak Cantonese [18]. Even though, Mandarin and English are two highly recommended languages to learn. What is concretely applied in several schools by providing courses in these languages [6]. It is recommended for schools with multilingual courses to maintain a minimum background noise level.

This study uncovers, generally, that teachers had a higher speech level than normal, it was increased with noise level. This Lombard effect keeps the SNR consistently, but in this environment conditions, teachers are more likely to get vocal disorders by time, such vocal fold pathology. It damages the voice folds permanently and demand medical intervention [19]. In addition, it influences life quality of teachers and their performance at work [20].

\subsection{South Africa study}

This research indicates that, referring to the American Speech Language Hearing Association, noise levels in the selected schools surpassed recommended values [21]. It suggests that the adequate noise level for learning should be between 30 and $40 \mathrm{~dB}$ for an unoccupied classroom and maximum of $50 \mathrm{~dB}$ for an occupied classroom. Results mention the average noise level over the recording period that was $68 \mathrm{~dB}$ in the baseline recording phase, and in the intervention phase, it was $66.6 \mathrm{~dB}$.

A diminution in the average noise level was confirmed by the visual feedback system [9]. It enabled an auto-supervision of noise level inside the classrooms by both teachers and students. Learners with appropriate learning conditions characterized by lower noise levels showed excellent study results. Otherwise, high noise level leaded to long-term memory disorders, poor reading comprehension, hearing damages and others [22]. Consequently, visual feedback can help, autonomously, to prevent the previous problems. 
Visual noise feedback, significantly, diminished noise level in the selected classrooms. Teachers' reviews confirmed that visual feedback ameliorates the teaching and learning operation, also the classroom environment. In South Africa, where students face many obstacles to study, such as multilingual country, increasing students' number and poor acoustical improvements, a visual feedback system may help to prepare a suitable learning environment [9].

\subsection{About Morocco}

From the two studies above, we can conclude that achieving an adequate studying environment for all the educational staff including students and teachers in first place requires a total engagement from all the collaborators. We observed from this review that using pedagogical actions combined with technological tools could both help not just to reduce noise levels but maintain it to the recommended suitable limits. The studies presented in this article displayed various recommendations that took in consideration other factors such the country properties, population nature and most important is human factor. These recommendations can be very beneficial for Morocco since there has not yet been a serious step towards reducing noise pollution in school institutions, neither from the government nor from the community. This article would be a first open door to the amelioration of the Moroccan school and the Moroccan university. For this purpose, we can start, for example, by modifying the law texts on noise pollution. The actual one [23] that organizes noise pollution in its Article 47, doesn't specify a measurable level neither a method to correctly identify and define a noise source. In addition, an improvement of the infrastructure and a refurbishment of the school buildings are required for better learning and teaching. Without forgetting the collaboration of every person to improve the school environment, since it is a fundamental factor for the success of the educational project.

\section{CONCLUSSION}

Nowadays, Noise Pollution at School Environment is one of the trending topics in the educational system. Taking into consideration that noise pollution is a serious issue spreading slightly into every part of our life. There should be a pause to observe the grave damages that affect the physiological side of us, like hearing loss, threshold shift, cardiovascular health issues and others [24]. In addition, the psychological side such as stress, annoyance, sleeping disorders and others [25]. Therefore, we must take into action solutions in the short term, such as developing low-noise products, using earplugs or earmuffs and the most important thing is to reach a high level of awareness in order to decrease noise pollution. Also, solutions in the long term like refurbishment, double glazed glass windows, soundproofing the locations. The main solution stills to reach a stage in which every collaborator in the educational system develop an auto-control of their noise emission in order to stop these troubles at first and ameliorate the state of the human versus this kind of danger.

There are various effects of noise pollution on the Moroccan educational system. The students, the teachers, and the administration staff, especially the younger ones suffer from this issue without knowing that. It is like the slow death diseases. We should be aware that noise pollution in the scholar environment is not only affecting the performance of the educational system staff, but also diminishing the motivation to build a good educational future.

To reduce the negative consequences of this problem in Morocco specifically, solutions must be taken immediately, such as:

- Adopting pedagogical intervention and behavioural training.

- Using visual feedback system to supervise noise level inside classrooms.

- Utilizing amplification systems to offer suitable SNR for the teaching and learning process.

- Installing modified measures such acoustical improvements for schools, and others.

To sum up with, change start with us, so, in order to live under suitable conditions, we should rethink about our habitudes and try to switch from oneself interest to the favour of everyone including the present and the future generations.

This study was carried out within the framework of the APPRENDRE Program/project $\mathrm{n}^{0}$. 95 funded by the Agence Universitaire de la Francophonie (AUF) and Ibn Khaldoun program (IK/2018/50)

Our thanks to everyone who has contributed directly or indirectly to the success of this research.

\section{References}

1. Smaldino JJ, Crandell CC, Kreisman BM, John AB, Kreisman NV, Thieme. Room acoustics for listeners with normal hearing and hearing impairment, 418-51 (2008)

2. S. Cheryan, S. Ziegler, V. Plaut, A. Meltzoff, PIBBS. Designing Classrooms to Maximize Student Achievement, (2014)

3. S. Cheryan, S. Ziegler, V. Plaut, A. Meltzoff, Policy Insights Behav. Brain Sci, Designing classrooms to maximize student achievement, 1, 4-12 (2014)

4. M. Ariani, F. Mirdad, Int. Educ. Stud, The E_ect of School Design on Student Performance, 9, 175 (2015)

5. World Health Organization, Regional Office for SouthEast Asia, http://www.searo.who.int/EN/Section1174 /Section1458.htm accessed (17 July 2009) 
6. K. Chan, C. Li, E. Ma, E. Yiu, B. McPherson, Noise \& Health, Noise levels in an urban Asian school environment, 17, 48-55 (2015)

7. P. Newman, J. Kenworthy, Island Press, Sustainability and Cities: Overcoming Automobile Dependence. Washington, DC, (1999)

8. I. Cañete-Medina, ASOCE, Are Asian cities leading the way to sustainable mobility?, 1520 (2008)

9. J. Van Tonder, N. Woite, S. Strydom, F. Mahomed, D, SAJOCEW, Effect of visual feedback on classroom noise levels, 6, 265 (2015)

10. Prakash, S., Rangasayee, R. \& Jeethendra, P., 2011. 'Low cost assistive noise level indicator for facilitating the learning environment of school going learners with hearing disability in inclusive educational setup', Indian Journal of Science and Technology 4(11), 1495-1504.

11. G. Rosenberg, P. Blake-Rahter, J. Heavner, L. Allen, B. Redmond, J. Phillips, K. Stigers, J Educ Audiol, Improving Classroom Acoustics (ICA): A three-year FM sound field classroom amplification study, 7, 8-28 (1999)

12. Y. Choi, B. McPherson, Int J Disabil Dev Educ, Noise levels in Hong Kong primary schools: Implications for classroom listening, 52, 34560 (2005)

13. E. Greenland, B. Shield, J Acoust Soc Am, A survey of acoustic conditions in semi open plan classrooms in the United Kingdom, 130, 1399-410 (2011)

14. C. Crandell, J. Smaldino, Lang Speech Hear Serv Sch, Classroom acoustics for children with normal hearing and with hearing impairment, 31, 362-70 (2000)

15. M. Picard, J. Bradley, Audiology, Revisiting speech interference in classrooms, 40, 22144 (2001)

16. P. Woolner, E. Hall, Int J Environ Res Public Health, Noise in schools: A holistic approach to the issue, $7,3255-69$ (2010)

17. S. Hygge, Copenhagen: National Institute of Public Health, Summary of the non-auditory effects of noise on children's health, 162-8 (2002)

18. Censu s and Statistics Department, The Government of the Hong Kong Special Administrative Region Hong Kong 2006 Population By-censusMain Tables; 2006, Available from: http://www.statistics.gov.hk/ publication/stat_report/population/B11200 512006XXXXB0400.pdf, (Last retrieved on 2014 Feb 13)
19. N. Roy, R. Merrill, S. Thibeault, R. Parsa, S. Gray, E. Smith, J Speech Lang Hear Res, Prevalence of voice disorders in teachers and the general population, 47, 281-93 (2004)

20. K. Verdolini, L. Ramig, Logoped Phoniatr Vocol, Review: Occupational risks for voice problems, 26, 37-46 (2001)

21. American Speech-Language Hearing Association (ASHA), 2005, Acoustics in educational settings: Position statement, American Speech-Language Hearing Association, viewed 30 June 2014, from http://www.asha.org/policy/PS200500028/

22. J. Dockrell, B. Shield, British Educational Research Journal, Acoustical barriers in classrooms: The impact of noise on performance in the classroom, 32, 509-525 (2006)

23. Dahir $n r^{\circ} 1-03-59$ of 10 rebii I 1424.

24. M. Hatfield, Vital Speeches of the day, Noise, 36, 1-5 (1969)

25. AIP Conference Proceedings 1855, 040002 (2017) 